\title{
Healthier doctors means healthier patients: CMA president-elect
}

\author{
n Cite as: CMAJ 2017 September 11;189:E1169. doi: 10.1503/cmaj.1095490
}

Posted on cmajnews.com on Aug. 23, 2017.

$\mathrm{T}$ hese are challenging times in the medical profession. The federal government's recently proposed tax reforms, which will affect doctors who incorporate their practices, is but one of many issues weighing heavily on the minds of Canadian physicians.

Stress levels are high. Burnout is on the rise. That is why, perhaps now more than ever, it is important for the Canadian Medical Association (CMA) to support doctors and advocate for their needs and well-being, according to Dr. Gigi Osler.

"My vision is that we can look after you, Canada's doctors, so that you can look after patients," said Osler, who was announced as the CMA's new presidentelect at the association's annual general council in Quebec City.

Osler is the head of otolaryngology (ENT)-head and neck surgery at St. Boniface Hospital in Winnipeg, Manitoba. She is also an assistant professor at the University of Manitoba, where she received her medical degree in 1992.

"I'm not a medical politician, but l've worked on the frontline of health care for the last 19 years as an ENT surgeon," said Osler. "I worked to provide the best possible care for patients, in the face of increasing wait times, widening gaps in health, and system reform."

Now, she is ready also to start working to provide support for Canadian doctors. Osler said she understands what they are going through.

"My work and my challenges are much the same as all of yours," she said. "My story is your story."

Doctors must come together and fight the challenges facing the medical profession, urged Osler. They must show strength and unity.

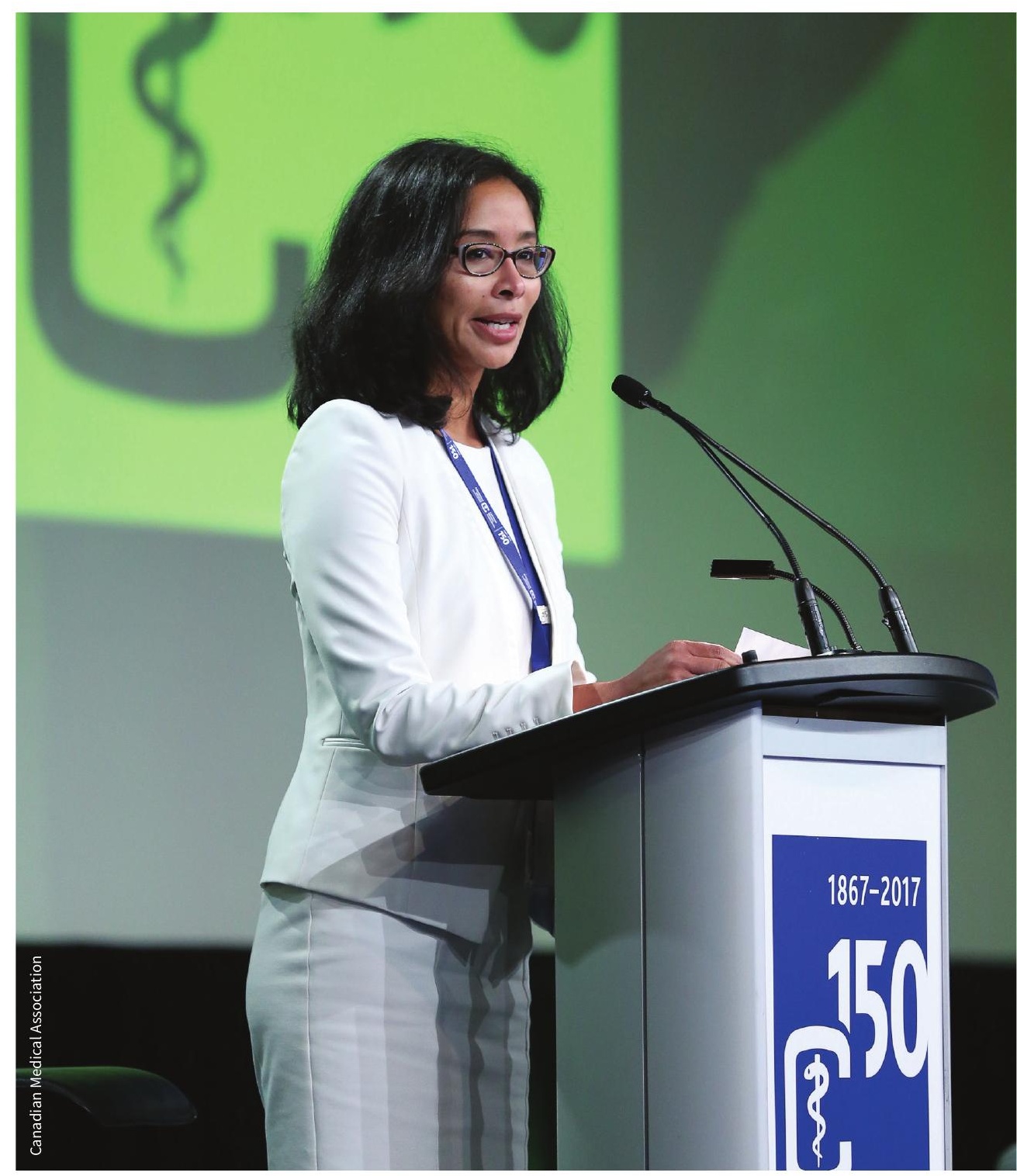

The CMA will look after doctors so doctors can look after patients, said CMA President-Elect Dr. Gigi Osler.

"We all want the same thing, to practise medicine in a system that does not tear us apart," she said. "Healthier doctors lead to healthier patients and healthier systems."
Osler will assume the role of CMA president at the association's next general council in Winnipeg in August 2018.

Roger Collier, CMAJ 